\title{
Functional Outcome of Isolated Hoffa Fractures Treated with Cannulated Cancellous Screw
}

\author{
Singh R, MS, Singh RB, MS, Mahendra M, DNB \\ Department of Orthopaedics, Sardar Vallabhbhai Patel Hospital, New Delhi, India \\ This is an open-access article distributed under the terms of the Creative Commons Attribution License, which permits unrestricted use,
distribution, and reproduction in any medium, provided the original work is properly cited \\ Date of submission: 25 July 2016 \\ Date of acceptance: 4 June 2017
}

\begin{abstract}
Introduction: Isolated Hoffa fracture is an infrequent injury and little research has been done on this subject. The purpose of this study was to evaluate the functional outcome and complications of surgically managed Hoffa fractures with cannulated cancellous screw.

Materials and Methods: Between 2011 and 2014, eight isolated Hoffa fractures in seven adult patients with mean age $39.8 \pm 11.9$ years (range $25-60$ years) were managed with cannulated cancellous screw of $6.5 \mathrm{~mm}$ diameter applied in anterior to posterior direction using swashbuckler and medial parapatellar approach for lateral and medial Hoffa fractures respectively. All patients were evaluated using knee evaluation score after two years or longer. Mean follow up was $28 \pm 3.8$ months (range 24-36 months).

Results: All fractures in the eight patients healed clinicoradiologically by the 16 th week with excellent result in $87.5 \%$ cases and good in $12.5 \%$ cases. By the end of union, the range of motion (ROM) of the knee was $0^{\circ}$ to $110^{\circ}$ except in two patients. One patient had ROM $10^{\circ}-100^{\circ}$ and other had $15^{\circ}-90^{\circ}$. Mean knee evaluation score was $87.5 \pm 10.4$. There was no incidence of non-union, infection or avascular changes in the patients or loss of reduction till final follow up.
\end{abstract}

Conclusion: Open reduction and fixation with two $6.5 \mathrm{~mm}$ cannulated cancellous screws with early mobilization yielded good functional outcome in isolated Hoffa fractures.

\section{Key Words:}

isolated Hoffa fracture, cannulated cancellous screw

\section{INTRODUCTION}

Isolated fracture of femoral condyles in the tangential plane is a rare injury and is usually accompanied with comminuted fractures of distal femoral condylar and supracondylar areas as a consequence of high energy trauma ${ }^{1-5}$. The exact mechanism causing this injury is still not well understood.
The combinations of forces including vertical thrust and twisting may bring about this intra-articular fracture of knee ${ }^{1-5}$. Also possibly, the direct impact to this area with some abduction component causes this injury ${ }^{6}$. The Hoffa fragment more commonly emerges from the lateral femoral condyle as it is principally involved in receiving direct or oblique impact with flexed $\mathrm{knee}^{6}$. This fracture is intrinsically unstable owing to bony instability and muscular pull ${ }^{5}$. As conservative treatment yields poor result, anatomical reduction and firm internal fixation is recommended for the management of this fracture ${ }^{6}$. We conducted this study to analyse the clinico-radiological and functional outcomes along with complications of surgically managed isolated Hoffa fracture with cannulated cancellous screw.

\section{MATERIALS AND METHODS}

Seven patients with eight isolated Hoffa fractures in adult knees between August 2011 and June 2014 (5 lateral and 3 medial Hoffa fragments) were included in the study. The mean age was of $39.8 \pm 11.9$ years. One patient had bilateral Hoffa injury involving medial condyle on both knees. All patients were evaluated with standard AP, lateral radiographs and CT scans. Patients with associated fractures, pathological Hoffa fractures or with previous history of fracture to the ipsilateral lower limb were excluded from the study.

All coronal fractures of the lateral femoral condyle were exposed by the swashbuckler (modified anterior) approach (Fig. 1) and the medial para-patellar approach was used for medial side Hoffa fracture. Fixation was carried out using $6.5 \mathrm{~mm}$ cannulated cancellous screws, inserted from nonarticular surface of femur or countersinking done if inserted from the articular surface. At least two screws were used with additional screws if necessary to augment the fixation. Post-operatively long knee braces were used for 
Table I: Demographic data of patients

\begin{tabular}{|lcccccc|}
\hline Patient no. & $\begin{array}{c}\text { Sex/Age } \\
\text { (years) }\end{array}$ & Side & $\begin{array}{c}\text { Femoral } \\
\text { condyle }\end{array}$ & $\begin{array}{c}\text { Surgical } \\
\text { delay }\end{array}$ & $\begin{array}{c}\text { Range of motion } \\
\text { (degrees) }\end{array}$ & $\begin{array}{c}\text { Knee Evaluation } \\
\text { Score }\end{array}$ \\
\hline 1 & $\mathrm{~F} / 42$ & Right & Lateral & 1 day & $0-110$ & 90 \\
2 & $\mathrm{M} / 25$ & $\begin{array}{c}\text { Right } \\
\text { Left (bilateral) }\end{array}$ & Lateral & 7 day & $0-120$ & 95 \\
3 & $\mathrm{M} / 37$ & Right (bilateral) & Medial & 3 day & $10-160$ & 95 \\
4 & $\mathrm{M} / 37$ & Left & Lateral & 3 day & $0-100$ & 80 \\
5 & $\mathrm{M} / 45$ & Right & Medial & 3 day & $0-110$ & 90 \\
6 & $\mathrm{~F} / 38$ & Left & Lateral & 7 day & $15-90$ & 95 \\
7 & $\mathrm{R} / 60$ & Lateral & 1 day & $0-120$ & 95 \\
8 & $\mathrm{M} / 30$ & & & & \\
\end{tabular}

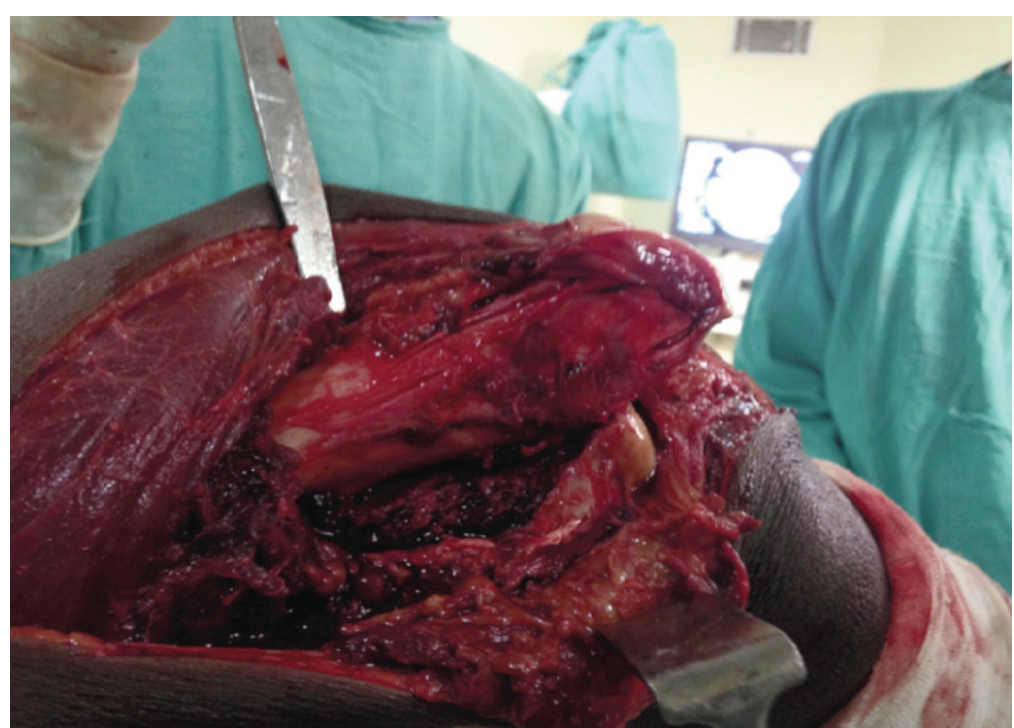

Fig. 1: Lateral approach exposing entire distal femoral condyle and fracture fragment. Quadriceps belly was spared and reflected medially. The incision used would not impede with the future knee arthroplasty.
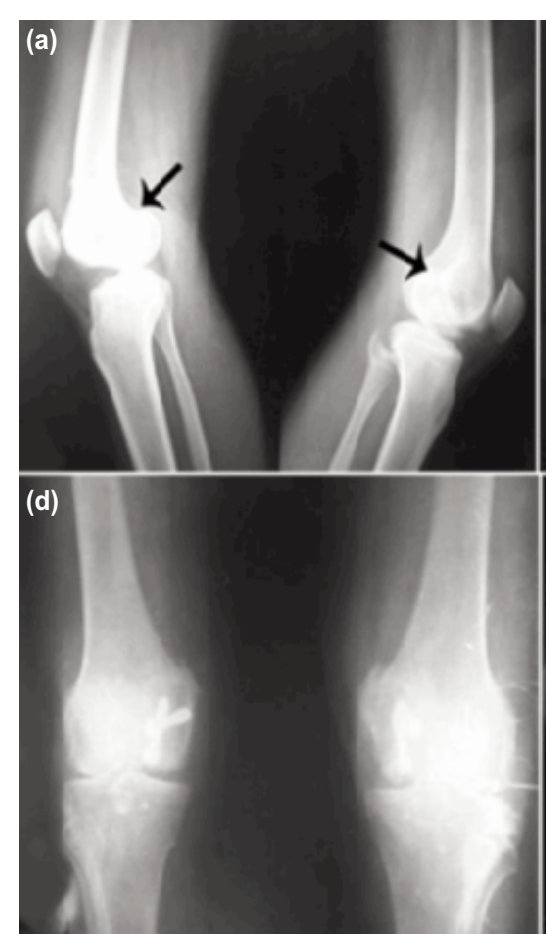

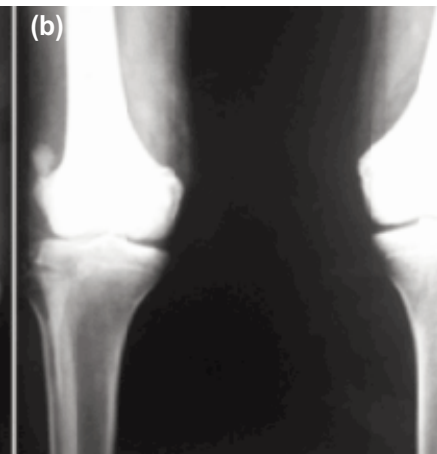

(e)

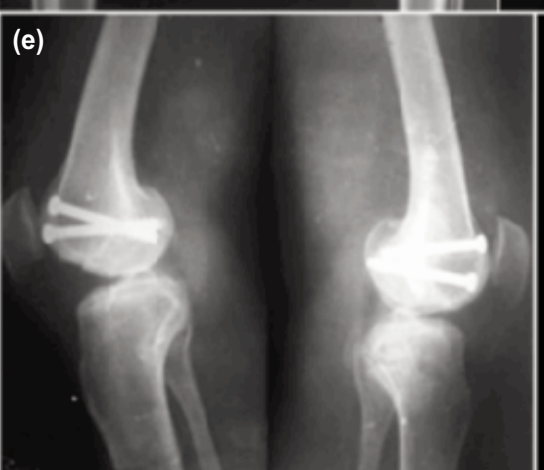

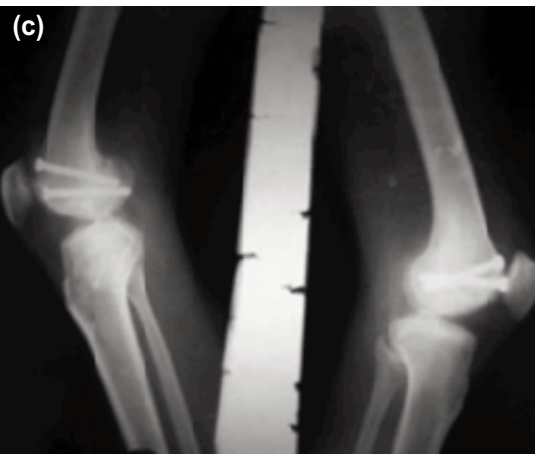

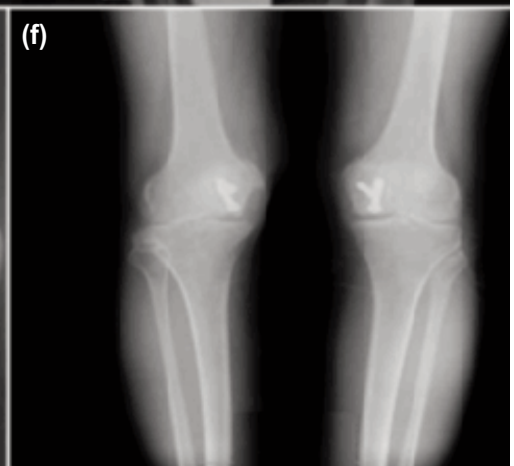

Fig. 2: (a, b) Case with bilateral Hoffa fracture involving medial condyle on both side with (black arrow), (c, d) Plain radiographs performed at 8 weeks showing fracture union and $(e, f)$ Radiological union was achieved by the end of 16 week. 

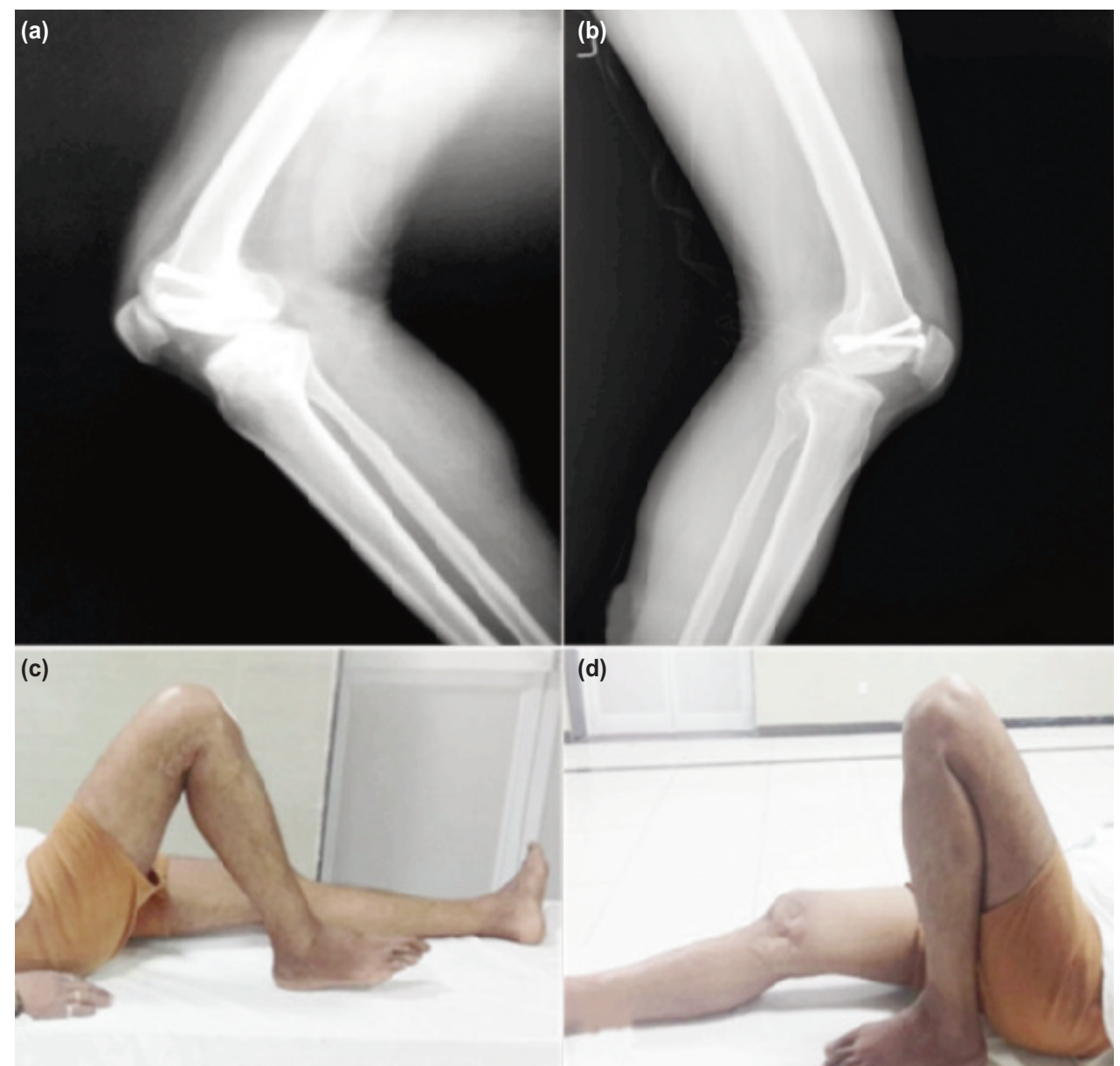

Fig. 3: Radiographs at 36 month follow up for (a) right and (b) left knee. Functional outcome by the end of 36 month were ROM in (c) right knee was $0-125^{\circ}$ and in (d) left was $10-160^{\circ}$.

immobilization and non-weight bearing range of motion (ROM) exercises were started as soon as the patient was comfortable enough. Weight bearing was allowed after six weeks. Initially partial weight bearing was allowed followed by gradual progression to unsupported walking over a period of time (12-16 weeks).

\section{RESULTS}

Five male and two female patients with five lateral side and three medial side Hoffa injury were included and evaluated in our study (Table I). Mean surgical delay was $3.5 \pm 2.5$ days (range 1-7 days). By 16 weeks, all fractures had united both clinically and radiologically (Fig. 2). There was no superficial or deep infection, non-union or avascular necrosis in any patients till last follow-up. There was no implant irritation requiring its removal in our study.

All patients had at least $0^{\circ}-110^{\circ}$ range of motion except two patients (Table I). One patient had an extension lag of $10^{\circ}$ and $\mathrm{ROM}$ was $10^{\circ}$ to $100^{\circ}$ and the other, with knee osteoarthritis and associated co-morbidities, had ROM of $15^{\circ}-90^{\circ}$. Average follow-up of $28 \pm 3.8$ months with long term follow-up of 36 month was available for three knees including the patient with bilateral Hoffa fracture (Fig. 3). Mean knee evaluation score was 87.5 \pm 10.35 (range: 95-65, Table I) while an excellent result was observed in 7 knees $(87.5 \%)$ and good in 1 knees $(12.5 \%)$.

\section{DISCUSSION}

Isolated Hoffa fracture is an infrequent injury and commonly emerges from lateral femoral condyle in comparison to medial condyle. Most authors are uncertain about the exact mechanism leading to this injury. These fractures commonly occur following motor vehicle accident ${ }^{6,7}$. In this study, six out of eight Hoffa fractures were seen in motor vehicle accidents with direct impact on the flexed knee. Lewis et al advocated that axial loading of lateral femoral condyle in a knee flexion of $90^{\circ}$ or more with some component of abduction produces this shear fracture ${ }^{7}$. Four out of seven patients were riding motorcycle and had collided with motor car, with the knee in flexion in their study ${ }^{6}$.

The fracture was dealt with based on the principles of intraarticular fracture management $t^{7,8}$. Operative fixation 
warranted a good functional outcome. Non-union and malunion have been reported when Hoffa fracture was managed conservatively ${ }^{6,7}$. Various authors described varying exposures for these fractures. Shi et al favoured an interval between iliotibial band and biceps tendon and Liebergall et al described Gerdy's tubercle osteotomy to improve fracture visualization and reduction ${ }^{9,10}$. With a more posterior approach there is a risk of neurovascular injury. We used the swashbuckler approach (modified anterior) with lateral parapatellar arthrotomy for lateral Hoffa fracture and medial para-patellar approach for medial Hoffa fracture. We ascertained that these approaches yielded ample visualization obligatory for optimum reduction and fixation with multiple cannulated cancellous screws. Lately some authors have shown promising results using arthroscopically assisted internal fixation of Hoffa fragment and advocate quicker recovery but it is still difficult to say that arthroscopically aided management had any definite benefit over orthodox open reduction ${ }^{11-13}$.

Hak DJ undertook the biomechanical assessment of internal fixation constructs using $3.5 \mathrm{~mm}$ and $6.5 \mathrm{~mm}$ screws and their data indicated that a double $6.5 \mathrm{~mm}$ screw provided meaningfully firm construct and at least two $3.5 \mathrm{~mm}$ screws should be used to approximate the biomechanical stability of single $6.5 \mathrm{~mm} \mathrm{screw}^{14}$. Jarit et al and Arastu et al show that fixation with postero-anterior oriented lag screw was biomechanically superior compared to antero-posterior oriented screw ${ }^{15,16}$. However, it is difficult in clinical practice as it involves more soft tissue dissection and putting the posterior neurovascular structures at risk. We used at least two $6.5 \mathrm{~mm}$ screws in the anterior-posterior direction as it was convenient with the approach and we did not come across any implant related issue upto the last follow up.
As far as we are aware, the reports of Lewis et al on seven lateral Hoffa fractures and Shi et al on 12 isolated Hoffa fracture represent the largest single group of patients studied ${ }^{6,8}$. Lewis et al utilized two cancellous screws and Shi et al augmented screws using locking plates and both showed good to fair functional outcome.

Limitation of this study is the small number of cases and relatively short follow-up period. We wish to accumulate larger number cases with long term follow up for a better evaluation and detailed analysis in future.

\section{CONCLUSION}

Swashbuckler and medial para-patellar approaches provide good exposure for reduction and fixation of these fractures. Open reduction and stable internal fixation of these coronal plane fractures lead to a good functional outcome. Two $6.5 \mathrm{~mm}$ screws make the construct stable for early mobilization.

\section{CONFLICT OF INTEREST}

The authors declare no conflicts of interest in the preparation of the manuscript. 


\section{REFERENCES}

1. Flanagin BA, Cruz AI, Medvecky MJ. Hoffa fracture in a 14-year-old. Orthopedics. 2011; 34(2): 138.

2. Dua A, Shamshery PK; Bicondylar Hoffa Fracture: Open Reduction Internal Fixation Using the swashbuckler approach. $J$ Knee Surg. 2010; 23: 21-3.

3. Haq RU, Modi P, Dhammi IK, Jain AK, Mishra P; Conjoint bicondylar Hoffa fracture in an adult. Indian J Orthop. 2013; 47(3): $302-6$.

4. Letenneur J, Labour PE, Rogez IM, Lignon J, Bainvel JV. Fractures de Hoffa: a propos de 20 observations. Ann Chir. 1978; 32(3-4): 213-9.

5. Payne R, Clark D, Wall S. Union after delayed presentation of a Hoffa fracture. Injury Extra. 2005; 36(7): 289-91.

6. Lewis SL, Pozo JL, Muirhead-Allwod WF. Coronal fractures of the lateral femoral condyle. J Bone Joint Surg Br. 1989; 71: 118-20.

7. Holmes SM, Bomback D, Baumgaertner MR. Coronal fractures of the femoral condyle: a brief report of five cases. $J$ Orthop Trauma. 2004; 18(5): 316-9.

8. Shi J, Tao J, Zhou Z, Gao M. Surgical treatment of lateral Hoffa fracture with a locking plate through the lateral approach. Eur J Orthop Surg Traumatol. 2014; 24(4): 587-92.

9. Liebergall M, Wilber JH, Mosheiff R, Segal D. Gerdy's tubercle osteotomy for the treatment of coronal fractures of the lateral femoral condyle. J Orthop Trauma. 2000; 14(3): 214-5.

10. Bali K, Mootha AK, Prabhakar S, Dhillon MS. Isolated Hoffa Fracture of the Medial Femoral Condyle in a Skeletally Immature Patient. A Case Report. Bull NYU Hosp Jt Dis. 2011;69(4):335-8.

11. Wallenbock E, Ledinski C. Indications and limits of arthroscopic man-agement of intraarticular fractures of the knee joint [German]. Aktuelle Traumatogie. 1993; 23: 97-101. [in German]

12. Lal H, Bansal P, Khare R, Mittal D. Conjoint bicondylar Hoffa fracture in a child: a rare variant treated by minimal invasive approach. J Orthop Traumatol. 2011; 12(2): 111-4.

13. McCarthy JJ, Parker RD. Arthroscopic reduction and internal fixation of a displaced intraarticular lateral femoral condyle fracture of the knee. Arthroscopy. 1996; 12: 224-7.

14. Hak DJ, Nguyen J, Curtiss S, Hazelwood S. Coronal fractures of the distal femoral condyle: a biomechanical evaluation of four internal fixation constructs. Injury. 2005; 36: 1103-6.

15. Jarit GJ, Kummer FJ, Gibber MJ, Egol KA. A mechanical evaluation of two fixation methods using cancellous screws for coronal fractures of the lateral condyle of the distal femur (OTA type 33B). J Orthop Trauma. 2006; 20: 273-6.

16. Arastu MH, Kokke MC, Duffy PJ, Korley RE, Buckley RE. Coronal plane partial articular fractures of the distal femoral condyle; current concepts in management. Bone Joint J Br. 2013; 95(9): 1165-71. doi: 10.1302/0301-620X.95B9.30656 